\title{
O processo de regionalização do SUS e a autonomia municipal no uso dos recursos financeiros: uma análise do estado de São Paulo (2009-2014)
}

The process of regionalization of SUS and municipal autonomy in the use of financial resources: an analysis of the state of São Paulo (20092014)

Ligia Schiavon Duarte', Áquilas Nogueira Mendes², Marília Cristina Prado Louvison

1 Instituto de Saúde - São Paulo (SP), Brasil.

ligia.duarte@uol.com.br

2 Universidade de São Paulo (USP), Faculdade de Saúde Pública - São Paulo (SP), Brasil. Pontifícia Universidade Católica de São Paulo (PUC-SP) Programa de Estudos PósGraduados em Economia Política e Departamento de Economia - São Paulo (SP), Brasil.

aquilasn@uol.com.br

3 Universidade de São Paulo (USP), Faculdade de Saúde Pública - São Paulo (SP), Brasil.

mariliampl@gmail.com
RESUMO Este artigo tem como objetivo compreender os efeitos que o financiamento das ações e dos serviços públicos vinculado às redes temáticas de atenção à saúde tem sobre as transferências de recursos federais para o Fundo Municipal de Saúde no interior do Bloco de financiamento da Média e Alta Complexidade (MAC), no sentido de identificar em que medida a implementação dessas redes restringiu a autonomia dos entes municipais e quais foram prioritárias com relação ao volume de recursos efetivamente transferidos. De forma geral, indaga-se se as transferências vinculadas às redes temáticas significaram um acréscimo aos recursos do Bloco MAC, mantendo assim preservada a parcela de uso mais autônomo dos entes municipais.

PALAVRAS-CHAVE Economia da saúde. Financiamento da assistência à saúde. Descentralização. Regionalização.

ABSTRACT This article aims to understand the effects that the financing of actions and public programs linked to the health care thematic networks have on the transfers of federal resources to the Municipal Health Fund within the Block of financing of the Medium and High Complexity $(M H C)$, in order to identify to what extent the implementation of these networks restricted the autonomy of municipal entities and which were prioritized in relation to the volume of resources effectively transferred. By and large, one has to question if the transfers linked to thematic networks meant an increase to the resources of the MHC Block, keeping thus the most autonomous portion of use of municipal entities preserved.

KEYWORDS Health economics. Health care financing. Decentralization. Regional health planning. 


\section{Introdução}

O debate sobre a forma de transferência de recursos do Fundo Nacional de Saúde (FNS) para os fundos subnacionais - Fundo Estadual de Saúde (FES) e Fundo Municipal de Saúde (FMS) - ganhou destaque com a recente aprovação pelo Ministério da Saúde da Portaria $\mathrm{n}^{\mathrm{o}} 3.992 / 2017$, que orienta o repasse em duas fontes, custeio e investimento, em substituição aos blocos de financiamento definidos pela Portaria $n^{0} 204$, do Ministério da Saúde, de 2007. Ainda que os artigos 17 e 18 da Lei Complementar $n^{\circ}$ 141, de $2012^{1}$, já orientassem sobre a necessidade de alteração na forma de repasse dos recursos da saúde, o embate entre os diferentes atores políticos quanto à defesa ou não de tais mudanças aponta para a necessidade de se resgatar o processo de descentralização da política de saúde pública a partir da distribuição equitativa dos recursos financeiros e de sua adequada alocação, e, ainda, sua influência na estruturação regional do Sistema Único de Saúde (SUS).

$\mathrm{O}$ aprofundamento ou não do processo de descentralização deve ser o eixo condutor dessa análise. Embora as propostas de descentralização da gestão das políticas públicas de saúde e da participação civil nesse processo já estivessem presentes no Brasil em meados do século XX, inspiradas por um período de efervescência política e social no cenário nacional ${ }^{2-4}$, a descentralização da gestão do sistema de saúde nacional, conhecida pela vertente da municipalização dos serviços de saúde, é levada a cabo ao longo dos anos 1990. Esse processo é resultado do compromisso da Constituição Federal de 1988 em promover o aumento do poder decisório das comunidades locais para apresentar e conduzir soluções para os seus problemas, buscando, assim, consolidar a democracia nascente ${ }^{5}$.

Ainda que a importância da descentralização da gestão do sistema e da participação da sociedade civil para a consolidação da democracia brasileira esteja em consonância com o debate mais geral do campo da saúde coletiva, diversos autores vêm apontando o 'excesso' de autonomia municipal como responsável pela fragmentação do sistema, o que dificultaria a gestão adequada da rede assistencial, sobretudo nos níveis de maior intensidade tecnológica ${ }^{6-8}$. Por outro lado, há autores que não reconhecem esse 'excesso', mas, ao contrário, identificam a limitação da autonomia dos entes subnacionais, sobretudo dos municípios, quando se consideram os critérios criados para as transferências dos recursos da União para os estados e municípios $^{9-13}$. Para estes autores, a despeito de o arcabouço legal e normativo que contempla o financiamento do SUS apontar, em diferentes momentos, para a importância de se garantir o uso dos recursos segundo as definições locais da política de saúde, a transferência fragmentada e condicionada em forma de incentivo ainda determina grande parte dos repasses da União.

Para Mendes et al. ${ }^{12}$, o propósito de garantir a autonomia dos estados e municípios no uso dos recursos a partir das transferências da esfera federal para os entes subnacionais, item explicitado na Lei Orgânica da Saúde ${ }^{14}$, não se efetivou. $\mathrm{O}$ arcabouço jurídico institucional que se seguiu, representado pelas Normas Operacionais Básicas (NOB), promoveu avanços ao induzir a transferência de recurso do FNS para os FES e para os FMSs, de forma regular e automática, no que se convencionou chamar de 'transferência fundo a fundo'. No entanto, se na NOB $93^{15}$ estavam previstos repasses a partir de um teto financeiro global, que permitia ao gestor municipal, em uma determinada condição de gestão, autonomia no uso dos recursos, na NOB $96^{16}$, os recursos passam a ser 'carimbados'. Isso significa que, se, incialmente, os repasses poderiam ser usados em todas as ações e os serviços de saúde, em todos os níveis de atenção, a partir da NOB 96, parte dos recursos passa a ser condicionada à adesão do ente subnacional às 'campanhas' incentivadas pelo Ministério da Saúde ${ }^{\mathbf{1 0}, 11}$. 
É possível afirmar que essa disputa pelo uso dos recursos financeiros transferidos pela União para os entes subnacionais, verificada ao longo da década de 1990, embrenha-se no processo de regionalização do SUS, que toma força a partir do início da década de 2000. Os marcos no arcabouço normativo desse processo, iniciado pelas Normas Operacionais da Assistência à Saúde - Noas 2001/200217, passando pelo Pacto pela Saúde $2006^{18}$ e chegando, mais recentemente, ao Decreto $\mathrm{n}^{0} \mathbf{7 . 5 0 8 ^ { 1 9 }}$, permitem observar a ampliação das transferências fragmentadas de recursos, efetivando repasses em forma de incentivo para uma grande variedade de componentes ${ }^{13}$.

Além da grande fragmentação na transferência de recursos, que restringe a autonomia dos entes municipais no uso desses recursos, é possível observar, também, que, a partir do Decreto $\mathrm{n}^{\circ} 7.508$, com o protagonismo assumido pela Rede de Atenção à Saúde $(\mathrm{RAS})^{\mathbf{2 0}}$, grande parte dos incentivos é voltada às ações e aos serviços da Média e Alta Complexidade Ambulatorial e Hospitalar (MAC). Essa perspectiva fica evidenciada quando se observa a importância das redes temáticas de atenção à saúde no direcionamento de transferências vinculadas ao processo de regionalização do SUS.

A transferência de recursos para as redes temáticas regionais incide de alguma forma sobre três blocos de financiamento, o da MAC, o de investimento e o da Atenção Básica (AB). No entanto, grande parte do montante disponibilizado às estratégias vinculadas às redes temáticas foi direcionada ao Bloco MAC ${ }^{13}$. Assim, mesmo que se considere que parte dos componentes da estrutura operacional das RAS seja transversal - AB, sistemas de apoio, sistemas logísticos e o sistema de governança -, ou seja, comum a todas as redes temáticas ${ }^{21}$, os recursos financeiros disponibilizados aos estados e municípios foram 'carimbados', sobretudo para o uso em procedimentos de média e alta complexidade, nos moldes definidos nas portarias que norteiam as redes temáticas.

Esses aspectos podem ser constatados quando se consideram as principais características do financiamento das quatro principais redes temáticas. A saber: a Rede Cegonha (RC), a Rede de Atenção à Urgência (RAU), a Rede de Atenção Psicossocial (Raps) e a Rede de Cuidados à Pessoa com Deficiências (Viver Sem Limite). A análise das portarias que orientam a transferência de recursos para essas redes temáticas evidencia a transferência de recursos para os governos subnacionais, priorizando o Bloco de financiamento da MAC, ou seja, constata-se que grande parte dos recursos foi direcionada ao cuidado mais especializado, conformado, sobretudo, pela assistência à saúde. Além disso, também é possível observar a fragmentação nas transferências desses recursos, efetivando repasses em forma de incentivo para uma grande variedade de componentes em cada uma das redes, em vez da transferência global de recursos. Tal fragmentação não apenas restringe a autonomia dos entes subnacionais, sobretudo o municipal, em determinar o modelo assistencial mais adequado ao seu território, considerando as necessidades de saúde locais, mas, ao contrário, submete-os a práticas de saúde determinadas de forma exógena ao território ${ }^{13}$.

Assim, com enfoque no repasse de recursos federais, o presente trabalho se propõe a discutir a preservação ou não das transferências globais no processo mais recente de regionalização do SUS. Para isso, torna-se necessário compreender os efeitos que o financiamento das ações vinculadas às redes temáticas regionais de atenção à saúde tem sobre as transferências de recursos federais para o FMS no interior do Bloco MAC, no sentido de identificar em que medida a implementação dessas redes restringiu a autonomia dos entes municipais e quais foram prioritárias com relação ao volume de recursos efetivamente transferidos.

Vale ressaltar que não se trata aqui de afirmar que o direcionamento de recursos, 
por parte do Ministério da Saúde, para níveis assistenciais predefinidos e ações específicas é ou não justificável. Para a análise aqui proposta, a verificação da forma de repasse dos recursos, se condicionados ou não, permite, sobretudo, identificar a ampliação ou restrição da autonomia dos municípios no uso desses recursos.

Dessa forma, cabe perguntar: as transferências vinculadas às redes temáticas significaram um acréscimo aos recursos do Bloco MAC, mantendo, assim, preservada a parcela de uso mais autônomo dos entes municipais?

Para responder a tal pergunta, optou-se por analisar os repasses realizados para os 645 municípios paulistas. O estado de São Paulo foi considerado território privilegiado para a compreensão dos efeitos que o financiamento das ações vinculadas às redes temáticas tem sobre as transferências de recursos no interior do Bloco MAC, tendo em vista a sua dinâmica econômica e a sua grande participação nas transferências do FNS. Conforme informações disponibilizadas no Portal Transparência, do Ministério da Saúde, o estado de São Paulo participou com mais de $20 \%$ do total dos repasses financeiros realizados pelo FNS - incluindo o FES, os FMSs paulistas e outros - no período 2009 a 2014, sendo que, ao se considerarem apenas as transferências destinadas ao Bloco MAC, o estado de São Paulo recebe mais de $22 \%$.

\section{Métodos}

Com vistas à compreensão dos efeitos do financiamento das ações vinculadas às redes temáticas na transferência dos recursos do FNS para os FMSs, o presente estudo empreendeu metodologia inédita ao propor uma nova agregação dos componentes do Bloco MAC. Manteve-se o componente Fundo de Ações Estratégicas e Compensações (Faec) e destacou-se do Limite Financeiro do MAC o Teto do Limite Financeiro, deixando agregadas as demais ações, os serviços e as estratégias que compõem o Limite Financeiro do MAC, resultando no 'Demais do Limite Financeiro' (tabela 1). Dessa forma, passou-se a tratar o Faec, o Teto do Limite Financeiro e o 'Demais do Limite Financeiro' como segmentos do Bloco MAC. Neste último, foram definidos seis grupos de ações e estratégias, conforme pode ser verificado na tabela 1 . Além de quatro grupos que contemplam as quatro redes temáticas - Rede Cegonha (RC), Rede de Atenção às Urgências (RAU), Raps e da Rede de Atenção à Pessoa com Deficiência (Rede Viver Sem Limites) -, foram definidos, ainda, dois outros grupos: o Serviço de Atendimento Móvel de Urgência (Samu) e o grupo Outros. O grupo Samu agrega as ações e estratégias vinculadas ao Samu que não fazem referência direta à RAU. É importante ressaltar que, mesmo considerando o Samu como um componente da RAU, no período anterior à implantação das estratégias vinculadas às redes temáticas, já estava previsto incentivo para esse serviço. Dessa forma, pode-se inferir que essas ações e estratégias teriam continuidade ainda que não fossem implementadas as redes temáticas. O último grupo, denominado 'Outros', é aquele que agrega as demais ações e estratégias que não se encaixam nos grupos anteriores. 
Tabela 1. Valor líquido das transferências do FNS para os FMSs no âmbito do Bloco MAC por ações e estratégias - estado de São Paulo (2009-2014)

\begin{tabular}{|c|c|c|c|c|c|c|c|}
\hline \multicolumn{2}{|c|}{ Ações, serviços e estratégias (em milhões de reais) } & Ano 2009 & Ano 2010 & Ano 2011 & Ano 2012 & Ano 2013 & Ano 2014 \\
\hline \multicolumn{2}{|l|}{ Total } & $3.687,89$ & $3.780,18$ & $4.072,18$ & $4.082,30$ & $4.069,09$ & $4.570,77$ \\
\hline \multicolumn{2}{|c|}{ Fundo de Ações Estratégicas e Compensação - Faec } & 559,27 & 491,16 & 544,44 & 576,80 & 546,02 & 555,05 \\
\hline \multicolumn{2}{|c|}{ Teto Municipal da Média e Alta Complexidade Ambulatorial e Hospitalar } & $3.002,23$ & $3.185,27$ & $3.394,85$ & $3.162,86$ & $2.783,94$ & $3.019,62$ \\
\hline \multicolumn{2}{|c|}{ Demais do Limite Financeiro } & 126,39 & 103,75 & 132,89 & 342,64 & 739,13 & 996,10 \\
\hline \multirow{2}{*}{$\begin{array}{l}\text { Rede Cego- } \\
\text { nha }\end{array}$} & Teto Municipal Rede Cegonha & - & - & - & 13,23 & - & - \\
\hline & Teto Municipal Rede Cegonha (RCE-RCEG) & - & - & - & 26,07 & 57,84 & 74,15 \\
\hline \multirow{7}{*}{$\begin{array}{l}\text { Rede de } \\
\text { Atenção às } \\
\text { Urgências }\end{array}$} & Rede de Urgência - Samu & - & - & - & 4,20 & - & - \\
\hline & $\begin{array}{l}\text { Serviços de Atendimento Móvel às Urgências Samu } 192 \\
\text { (RAU-Samu) - Municipal }\end{array}$ & - & - & - & - & 57,23 & 134,44 \\
\hline & $\begin{array}{l}\text { Serviços de Atendimento Móvel às Urgências Samu } 192 \\
\text { (MAC) - Estadual }\end{array}$ & 84,73 & 68,19 & 94,14 & 119,07 & - & - \\
\hline & Teto Municipal Rede de Urgência & - & - & - & 29,68 & - & - \\
\hline & Teto Municipal Rede de Urgência (RAU-Hosp) & - & - & - & 34,80 & 173,29 & 241,86 \\
\hline & Teto Municipal Rede de Urgência (RAU-UPA) & - & - & - & 22,84 & 60,39 & - \\
\hline & Teto Municipal Limite UPA - PO 00098585 & - & - & - & - & 56,02 & 165,20 \\
\hline \multirow{3}{*}{$\begin{array}{l}\text { Rede de } \\
\text { Atenção } \\
\text { Psicossocial }\end{array}$} & Teto Municipal Rede Psicossocial & - & - & - & 21,11 & - & - \\
\hline & Teto Municipal Rede Psicossocial (RSM-CRAC) & - & - & - & 11,27 & 13,23 & 13,99 \\
\hline & Teto Municipal Rede Saúde Mental (RSME) & - & - & - & 11,16 & 108,61 & 169,32 \\
\hline \multirow{3}{*}{$\begin{array}{l}\text { Rede Viver } \\
\text { Sem Limite }\end{array}$} & Rede Viver Sem Limites - RDEF - CEO Estadual & - & - & - & 0,82 & 1,42 & - \\
\hline & Rede Viver Sem Limites - REDEF - CEO Municipal & - & - & - & - & 0,85 & 1,92 \\
\hline & Teto Municipal Rede Viver Sem Limites (RDEF) & - & - & - & 0,60 & 8,84 & 55,75 \\
\hline \multirow{3}{*}{$\begin{array}{l}\text { Serviço de } \\
\text { Atenção } \\
\text { Móvel de } \\
\text { Urgência }\end{array}$} & $\begin{array}{l}\text { Serviços de Atendimento Móvel às Urgências Samu } 192 \\
\text { (MAC) }\end{array}$ & - & - & - & - & 49,00 & - \\
\hline & $\begin{array}{l}\text { Serviços de Atendimento Móvel às Urgências Samu } 192 \\
\text { (MAC) - Municipal }\end{array}$ & - & - & - & - & 31,75 & 70,48 \\
\hline & $\begin{array}{l}\text { Serviços de Atendimento Móvel às Urgências Samu } 192 \\
\text { (RAU- Samu) - Estadual }\end{array}$ & - & - & - & 5,18 & 54,64 & - \\
\hline \multirow[t]{9}{*}{ Outros } & Aquisição de Produtos Médicos de Uso Único & - & - & - & 0,23 & - & 0,20 \\
\hline & Centros de Especialidades Odontológicas & 20,16 & 18,33 & 4,87 & - & - & - \\
\hline & CEO - Centro de Especialidades Odontológicas - Municipal & - & - & - & - & 10,88 & 30,86 \\
\hline & CEO - Centro de Especialidades Odontológicas Estadual & - & - & 16,56 & 22,18 & 13,40 & - \\
\hline & $\begin{array}{l}\text { Financiamento aos Centros de Referência em Saúde do Tra- } \\
\text { balhador }\end{array}$ & 21,50 & 17,23 & 17,32 & 16,40 & 16,69 & 8,40 \\
\hline & Pagamentos Administrativos (AlH) & - & - & - & 0,05 & 0,38 & 0,06 \\
\hline & Teto Municipal Limite Controle do Câncer - PO 00088585 & - & - & - & - & 0,11 & 0,41 \\
\hline & Teto Municipal Rede Brasil Sem Miséria (BSOR-SM) & - & - & - & 3,73 & 21,89 & 26,39 \\
\hline & $\begin{array}{l}\text { Teto Municipal Rede Prev Diag Trat Câncer Colo de Mama } \\
\text { (RCA-RCAN) }\end{array}$ & - & - & - & - & 2,68 & 2,67 \\
\hline
\end{tabular}

Fonte: Elaboração própria, com base em dados do Fundo Nacional de Saúde/MS.

Nota: Valores deflacionados pela média anual a preços de dezembro de 2014, conforme IGP-DI da FGV. 
Em resumo, é possível analisar o comportamento das transferências do FNS para os FMSs paulistas desagregando o Bloco MAC em três segmentos, o Faec, o Teto do Limite Financeiro, que propicia maior autonomia ao gestor municipal na definição do uso do recurso, e o 'Demais do Limite Financeiro', sendo este último desagregado em seis grupos: i) Rede Cegonha (RC); ii) Rede de Atenção às Urgências (RAU); iii) Rede de Atenção Psicossocial (Raps); iv) Rede de Atenção à Pessoa com Deficiência (Rede Viver Sem Limites); v) Samu; e vi) 'Outros'.

Os repasses foram analisados no período 2009-2014, sendo que os três primeiros anos representam o período anterior ao início dos repasses vinculados às redes temáticas (2009-2011), e os três últimos anos, o período posterior (2012-2014).

As informações dos repasses financeiros realizados pelo FNS no período analisado foram acessadas no site do próprio FNS ao longo do mês de setembro de 2015 e foram trabalhadas em planilhas eletrônicas (Excel e Acess).

Para a melhor compreensão dos efeitos do financiamento das ações vinculadas às redes temáticas regionais nas transferências do FNS para os FMSs paulistas a partir de 2012, os valores foram deflacionados utilizando-se o Índice Geral de Preços-Disponibilidade Interna (IGP-DI) da Fundação Getúlio Vargas (FGV), com base em agosto de 1994, valor médio do ano, convertido a preços de dezembro de 2014. Dessa forma, torna-se possível a comparação da série histórica em valores reais.

\section{Resultados}

A partir de 2012, inicialmente, serão apresentadas as mudanças ocorridas no período 2009-2014 nas transferências totais, desagregando, também, o Bloco Atenção Básica (AB) e o Bloco MAC. Esse exercício se faz necessário para evidenciar a importância que assume o Bloco MAC na transferência de recursos da União para os municípios paulistas no período analisado.

Em seguida, enfatizar-se-á o comportamento dos segmentos propostos no interior do Bloco MAC, ou seja, do Faec, do Teto do Limite Financeiro e do 'Demais do Limite Financeiro', verificando a preservação ou não dos repasses globais no período em análise.

Por fim, será analisado o comportamento dos seis grupos que compõem o 'Demais do Limite Financeiro', onde se inserem as estratégias vinculadas às redes temáticas, de forma a se identificar quais foram as estratégias que condicionaram o uso dos recursos.

\section{As transferências do FNS aos FMSs paulistas por bloco de financiamento}

Entre 2009 e 2014, ocorreu a transferência média anual de 6,5 bilhões de reais do FNS para os FMSs paulistas, contemplando todos os blocos de financiamento previstos. Considerando todo o período analisado, verifica-se o crescimento anual de 4,2\% dos recursos transferidos pelo governo federal aos governos municipais paulistas. $\mathrm{O}$ crescimento total dos repasses ao longo do período deve-se, sobretudo, àqueles realizados no âmbito dos Blocos $\mathrm{AB}$ e MAC, que, juntos, respondem por repasse anual médio de cerca de 5,9 bilhões de reais, ou seja, mais de $90 \%$ do total dos recursos, apresentando taxas médias de crescimento anual de 4,6\% e 3,6\%, respectivamente. Mesmo considerando que a taxa média de crescimento anual do Bloco $\mathrm{AB}$ seja maior do que a do MAC, este último recebe mais do que o dobro de recursos do primeiro (gráfico 1). 
Gráfico 1. Evolução das transferências do FNS para os FMSs por Blocos de financiamento da $A B$ e da MAC - estado de São Paulo (2009-2014)

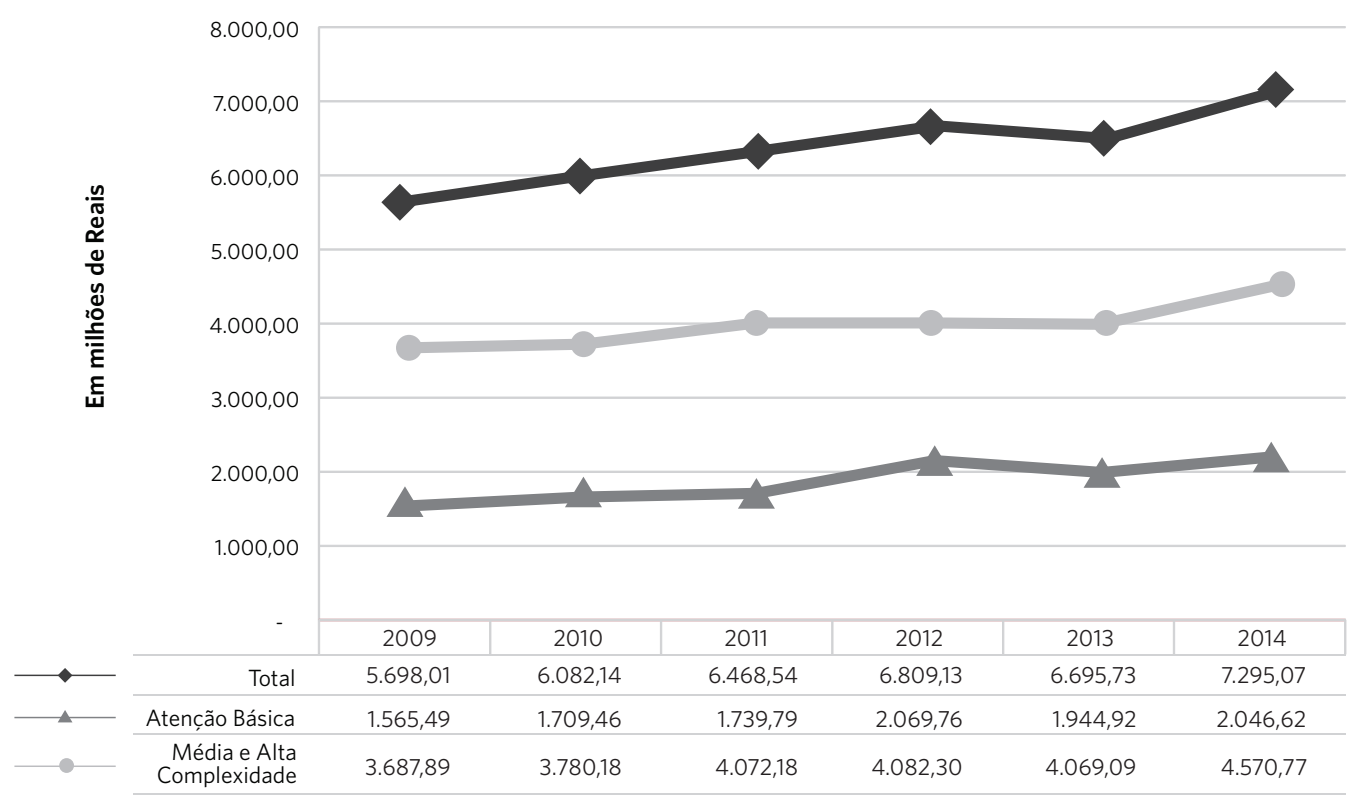

Fonte: Elaboração própria, com base em dados do Fundo Nacional de Saúde/MS.

Nota: Valores deflacionados pela média anual a preços de dezembro de 2014, conforme IGP-DI da FGV.

O gráfico 1 permite verificar a tendência de crescimento do total das transferências do FNS para os FMSs paulistas até 2012, ocorrendo uma ligeira queda em 2013 e voltando a crescer em 2014. É possível observar que a queda observada em 2013 é reflexo tanto do comportamento dos repasses para o Bloco da AB como para o MAC, com a diferença de que, com relação ao primeiro, a recuperação que ocorre em 2014 não atinge o patamar das transferências realizadas em 2012, enquanto que o segundo apresenta crescimento real expressivo nesse período. Em suma, as transferências do FNS para os FMSs paulistas no Bloco da $A B$ se mantêm praticamente estagnadas no período 2012-2014. Já o Bloco MAC, cujas transferências se mantêm praticamente estagnadas no período 2011-2013, apresenta crescimento real expressivo em 2014, sendo responsável, em grande medida, pelo comportamento das transferências totais no final do período analisado.

\section{As transformações nas transferên- cias do FNS para os FMSs paulistas no Bloco MAC}

Ao se considerar a participação do Bloco MAC no total das transferências do governo federal para os FMSs paulistas ao longo do período, observa-se uma relativa estabilidade, uma vez que o Bloco responde por $60 \%$ ou mais dos repasses. No entanto, a análise desagregada dos segmentos propostos, ou seja, desagregando o Faec, o Teto do Limite Financeiro e o 'Demais do Limite Financeiro', permite demonstrar a diminuição relativa da participação do Teto do Limite Financeiro ao longo do período analisado.

Conforme exposto no gráfico 2, a análise do crescimento real das transferências do FNS para os FMSs paulistas no Bloco MAC, desagregado por segmentos, permite identificar o expressivo crescimento do 'Demais do Limite Financeiro' ao longo 
do período 2012-2014. Vale ressaltar que, nos dois primeiros anos do período (2012 e 2013), esse crescimento foi acompanhado da diminuição, em termos reais, dos recursos direcionados para o Teto do Limite Financeiro, que só volta a crescer em 2014, mesmo não retomando os patamares atingidos até 2012 .

Gráfico 2. Evolução das transferências do FNS para os FMSs no âmbito do Bloco MAC pelos segmentos Faec, Teto do Limite Financeiro e Demais do Limite Financeiro - estado de São Paulo (2009-2014)

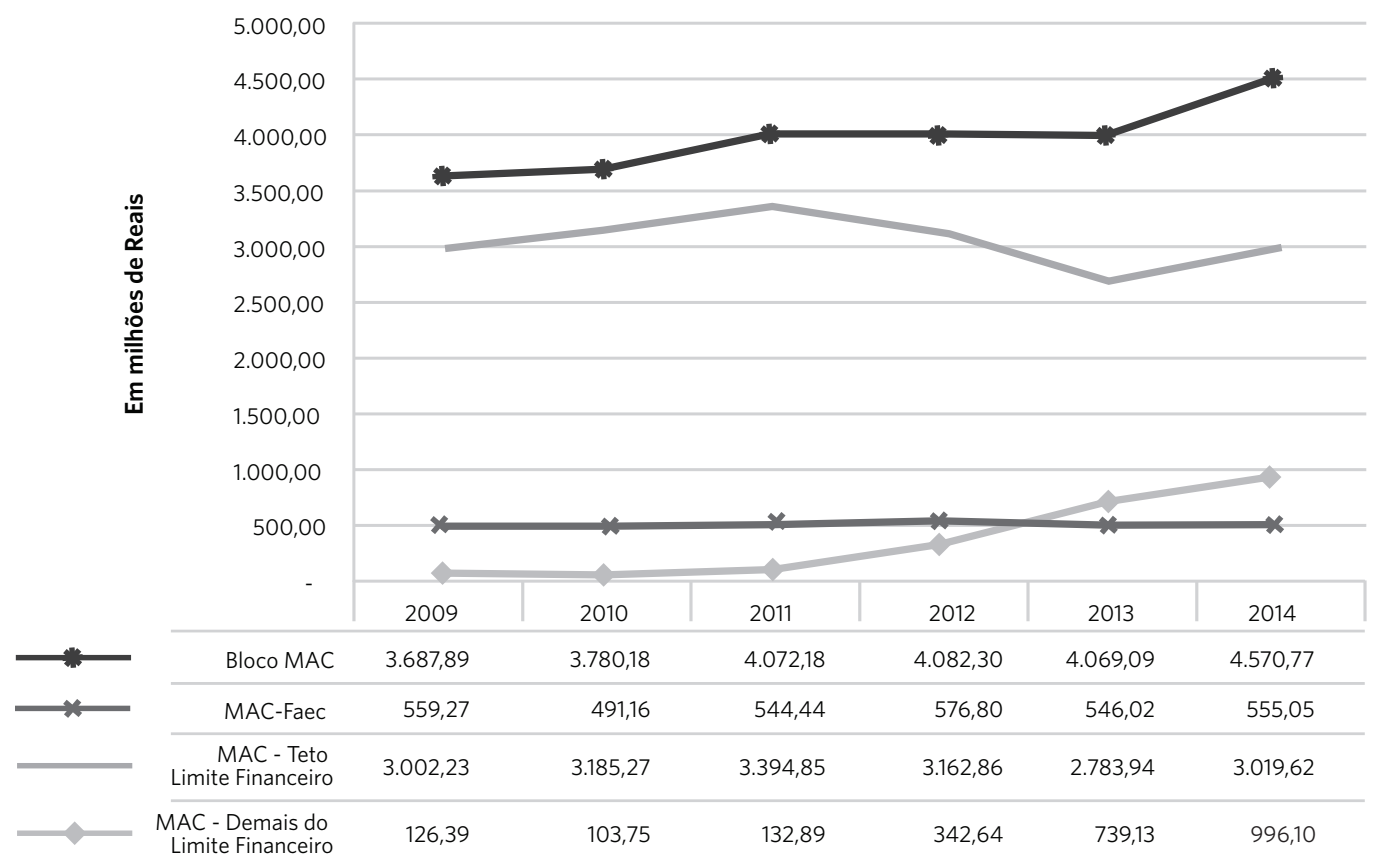

Fonte: Elaboração própria, com base em dados do Fundo Nacional de Saúde/MS

Nota: Valores deflacionados pela média anual a preços de dezembro de 2014, conforme IGP-DI da FGV.

Assim, é possível afirmar que a lógica de repasse global, reconhecida no Teto do Limite Financeiro, foi sendo descaracterizada a partir de 2012, com a implantação e a expansão das estratégias vinculadas às redes temáticas, sendo privilegiado o repasse de recursos na forma de incentivos, que exigem a adesão dos municípios às 'campanhas' incentivadas pelo Ministério da Saúde.

Sucintamente, pode-se afirmar que, com relação às transferências de recursos do FNS para os FMSs paulistas para o Bloco MAC, é possível observar uma clara ampliação da importância do 'Demais do Limite Financeiro', tanto relativa quanto absoluta, a partir de 2012 (gráfico 2). Diante desse fato, torna-se necessário compreender quais ações e estratégias, que conformam o componente Limite Financeiro do MAC, induzem esse processo. É o que será feito a seguir.

\section{As transformações nas transferên- cias do FNS para os FMSs paulistas no item 'Demais do Limite Financeiro'}

A análise dos grupos que compõem o 'Demais do Limite Financeiro' demonstra que, até 2011, esse segmento era formado, sobretudo, pelo SAMU e que, em 2012, os recursos direcionados para as estratégias 
vinculadas às redes temáticas ultrapassam o valor dos recursos direcionados às ações e estratégias contempladas no período anterior (gráfico 3).

Gráfico 3. Transferências do FNS para os FMSs no âmbito do 'Demais do Limite Financeiro' segundo grupos - estado de São Paulo (2009-2014)

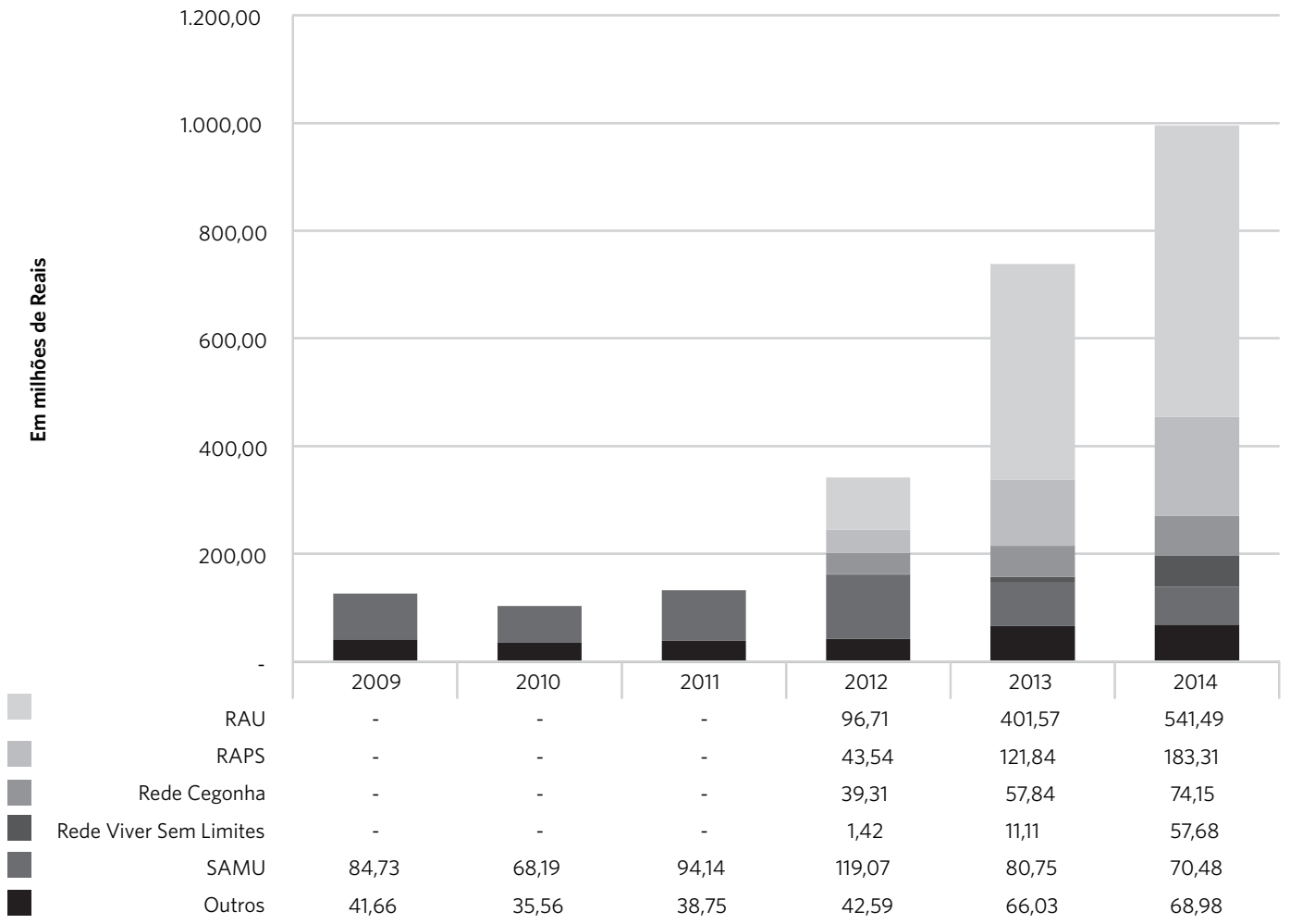

Fonte: Elaboração própria, com base em dados do Fundo Nacional de Saúde/MS

Nota: Valores deflacionados pela média anual a preços de dezembro de 2014, conforme IGP-DI da FGV.

A partir de 2012, é possível observar o grande crescimento das transferências do FNS para os FMSs paulistas para as redes temáticas, sobretudo para a RAU. O gráfico 3 demonstra que a Raps, a Rede Cegonha e a Rede Viver Sem Limites, ainda que ao longo do tempo também ampliem suas participações no 'Demais do Limite Financeiro', juntas, não atingem o recurso direcionado à RAU.

Em síntese, a dimensão da mudança no padrão de repasse dos recursos no Bloco de financiamento MAC pode ser observada quando se considera o acréscimo dos recursos transferidos pelo FNS para os FMSs considerando dois períodos, o anterior à implementação das redes temáticas e o período posterior.

A tabela 2 demonstra que esse acréscimo foi da ordem de 1,18 bilhão de reais a preços de dezembro de 2014. Vale ressaltar que, enquanto o subsegmento Teto do Limite Financeiro apresentou diminuição real dos recursos repassados, o Faec e, sobretudo, o 'Demais do Limite Financeiro' apresentaram ampliação. Observa-se que o aumento real dos recursos repassados para o 'Demais do Limite Financeiro' está associado, principalmente, às estratégias vinculadas às redes temáticas. 
Tabela 2. Valor líquido das transferências do FNS para os FMSs no âmbito do Bloco MAC por componentes e grupos do 'Demais do Limite Financeiro' nos dois períodos considerados - estado de São Paulo (2009-2014)

\begin{tabular}{lrrrrrrr}
\hline \multirow{2}{*}{$\begin{array}{l}\text { Modalidade do repasse } \\
\text { (em milhões de reais) }\end{array}$} & Abs. & Part. & Abs. & Part. & Abs. & Part. & Diferença \\
\cline { 2 - 6 } Total geral & $\mathbf{1 1 . 5 4 0 , 2 5}$ & $\mathbf{1 0 0 , 0 \%}$ & $\mathbf{1 2 . 7 2 2 , 1 6}$ & $\mathbf{1 0 0 , 0} \%$ & $\mathbf{2 4 . 2 6 2 , 4 0}$ & $\mathbf{1 0 0 , 0 \%}$ & $\mathbf{1 . 1 8 1 , 9 1}$ \\
\hline Faec & $\mathbf{1 . 5 9 4 , 8 7}$ & $\mathbf{1 3 , 8 \%}$ & $\mathbf{1 . 6 7 7 , 8 6}$ & $\mathbf{1 3 , 2 \%}$ & $\mathbf{3 . 2 7 2 , 7 3}$ & $\mathbf{1 3 , 5 \%}$ & $\mathbf{8 3 , 0 0}$ \\
\hline Limite Financeiro & $\mathbf{9 . 9 4 5 , 3 8}$ & $\mathbf{8 6 , 2} \%$ & $\mathbf{1 1 . 0 4 4 , 2 9}$ & $\mathbf{8 6 , 8} \%$ & $\mathbf{2 0 . 9 8 9 , 6 7}$ & $\mathbf{8 6 , 5 \%}$ & $\mathbf{1 . 0 9 8 , 9 1}$ \\
\hline Teto Municipal da MAC & $9.582,35$ & $83,0 \%$ & $8.966,42$ & $70,5 \%$ & $18.548,77$ & $76,5 \%$ & $-615,94$ \\
Demais do limite & 363,03 & $3,1 \%$ & $2.077,87$ & $16,3 \%$ & $2.440,90$ & $10,1 \%$ & $1.714,85$ \\
RAU & - & $0,0 \%$ & $1.039,77$ & $8,2 \%$ & $1.039,77$ & $4,3 \%$ & $1.039,77$ \\
Raps & - & $0,0 \%$ & 348,70 & $2,7 \%$ & 348,70 & $1,4 \%$ & 348,70 \\
Rede Cegonha & - & $0,0 \%$ & 171,30 & $1,3 \%$ & 171,30 & $0,7 \%$ & 171,30 \\
Rede Viver Sem Limites & - & $0,0 \%$ & 70,21 & $0,6 \%$ & 70,21 & $0,3 \%$ & 70,21 \\
Samu & 247,07 & $2,1 \%$ & 270,30 & $2,1 \%$ & 517,37 & $2,1 \%$ & 23,24 \\
Outros & 115,96 & $1,0 \%$ & 177,60 & $1,4 \%$ & 293,56 & $1,2 \%$ & 61,64 \\
\hline
\end{tabular}

Fonte: Elaboração própria, com base em dados do Fundo Nacional de Saúde/MS.

Nota: Valores deflacionados pela média anual a preços de dezembro de 2014, conforme IGP-DI da FGV.

Observa-se que o aumento real dos recursos repassados para o subsegmento 'Demais do Limite Financeiro’ está associado, principalmente, às estratégias vinculadas às redes temáticas, sobretudo a RAU. É essa rede que recebe a maior parcela dos recursos quando se analisa o total dos recursos transferidos para o 'Demais do Limite Financeiro', ao longo do período 2009-2014, seguido pelo Samu. Apenas a título de ilustração, é possível observar que, dos $10,1 \%$ dos recursos direcionados ao 'Demais do Limite Financeiro’, 6,4\% são transferidos para ações e estratégias que conformam o grupo RAU e o Samu, juntos.

Ao se considerar a natureza comum da atenção à saúde da RAU e do Samu, e que para esse último já havia incentivos programados no período 2009-2011, que se mantêm no período 2012-2014, é possível afirmar que a implantação das redes temáticas, com relação aos incentivos financeiros, reforçou uma lógica assistencial que já operava no período anterior.

\section{Conclusões}

Uma das primeiras constatações dos efeitos que o financiamento das ações vinculadas às redes temáticas tem sobre as transferências de recursos para os FMSs paulistas no interior do Bloco MAC é a ampliação das transferências na forma de incentivos (recursos (carimbados'). Foi possível verificar que o Teto do Limite Financeiro, mais coerente com a lógica de repasse global, perde importância, tanto relativa como absoluta, ao mesmo tempo que aumenta os recursos direcionados às estratégias vinculadas às redes temáticas a partir de 2012. Ou seja, ainda que se observe o crescimento de recursos no Bloco MAC no período 2012-2014, em comparação com o período 2009-2011, de forma concomitante, verifica-se a diminuição dos recursos para o Teto do Limite Financeiro.

Foi possível constatar, também, que a maior parte desses recursos foi direcionada para a Rede de Atenção à Urgência. Ainda que, ao longo do tempo, a Rede de Atenção 
Psicossocial, a Rede Cegonha e a Rede Viver Sem Limites também ampliem suas participações no total dos recursos transferidos, juntas, não atingem o recurso direcionado à RAU. O montante de recursos direcionados à RAU ganha relevância quando se observa que um dos principais componentes dessa linha de cuidado é o Samu. Haja vista que esse já era objeto de incentivos no Bloco MAC no período anterior à implementação das redes temáticas, e se mantém no período posterior, depreende-se daí que, com relação à parte considerável dos incentivos voltados às redes temáticas no estado de São Paulo, observa-se a ratificação de uma estratégia de atenção que já operava no período anterior.

Tais constatações sugerem que, ao invés do financiamento das redes temáticas trazer novos recursos para a promoção de transformações nas formas de organização assistencial de caráter regional até então vigentes, ele reforça os modelos de atenção hegemônicos no Brasil, quais sejam: o médico-assistencial e o sanitarista, que não privilegiam os determinantes mais gerais da situação de saúde da população $0^{22,23}$.

Junta-se a isso o fato de o financiamento das redes ter redirecionado recursos que, outrora, possibilitavam maior autonomia do ente municipal, ou seja, que, em alguma medida, permitiam aos atores locais o planejamento e a programação das ações de saúde a partir do reconhecimento dos problemas de saúde da população. Mais especificamente, que permitiam o reconhecimento dos elementos endógenos à localidade.

Depreende-se daí que o financiamento mais recente do processo de regionalização do SUS, ao invés de representar um fator de aprofundamento da descentralização da política de saúde nacional, na perspectiva de oferecer maior autonomia municipal no uso dos recursos financeiros, significou a ampliação da transferência fragmentada e condicionada em forma de incentivo, sobretudo para ações de saúde de média e alta complexidade. 


\section{Referências}

1. Santos L, Mendes AN. Notas Técnico-Jurídicas Sobre Critérios e Metodologia de Rateio dos Recursos Federais para os Estados e Municípios no SUS. BDM. 2014 Set; 30(9):647-664.

2. Luz TM. Duas questões permanentes em um século de políticas de saúde no Brasil republicano. Ciênc Saúde Colet. 2000; 5(1):293-312.

3. Escorel S, Teixeira LA. História das políticas de saúde no Brasil de 1822 a 1963: do Império ao desenvolvimentismo populista. In: Giovanella L et al., organizadores. Políticas e Sistemas de Saúde no Brasil. Rio de Janeiro: Fiocruz; 2008. p. 279-322.

4. Souza NPC. A $3^{\text {a }}$ Conferência Nacional de Saúde (1963): antecedentes para um Sistema Nacional de Saúde Público e Descentralizado [dissertação]. Rio de Janeiro: Fundação Oswaldo Cruz; 2014. 160 p.

5. Arretche MTS. Estado federativo e políticas sociais: determinantes da descentralização. 3. ed. Rio de Janeiro: Revan; São Paulo: Fapesp; 2011.

6. Silva MVCP, Mendes EV. Pacto de gestão: da municipalização autárquica à regionalização cooperativa. Belo Horizonte: Secretaria de Estado de Saúde de Minas Gerais; 2004.

7. Dourado DA, Elias PEM. Regionalização e dinâmica política do federalismo sanitário brasileiro. Rev Saúde Pública. 2011; 45(1):204-211.

8. Viana ALD, Ibañez N, Elias PEM et al. Novas perspectivas para a regionalização da saúde. São Paulo Perspect. 2008 Jan-Jun; 22(1):92-106.

9. Carvalho G. A inconstitucional administração pós-constitucional do SUS através de normas operacionais. Ciênc Saúde Colet. 2001; 6(2):435-444.

10. Barros E. Financiamento do sistema de saúde no Brasil: marco legal e comportamento dos gastos. In: Ministério da Saúde. Série Técnica Projeto de
Desenvolvimento de Sistemas e Serviços de Saúde. Brasília, DF: MS; 2003. p. 17-70.

11. Mendes AN. Financiamento, gasto e gestão do Sistema Único de Saúde (SUS): a gestão descentralizada semiplena e plena do Sistema municipal no Estado de São Paulo (1995-2001) [tese]. Campinas: Universidade Estadual de Campinas; 2005. 422 p.

12. Mendes NA, Leite MG, Marques RM. Discutindo uma Metodologia para a Alocação Equitativa de Recursos Federais para o Sistema Único de Saúde. Saúde Soc. 2011 20(3):673-690.

13. Duarte LS. Desenvolvimento desigual e a regionalização do SUS: uma análise territorial dos recursos financeiros para as redes de atenção à saúde no Estado de São Paulo (2009-2014) [tese]. São Paulo: Universidade de São Paulo; 2016.

14. Brasil. Lei no 8.080, de 19 de setembro de 1990. Dispõe sobre as condições para a promoção, proteção e recuperação da saúde. Diário Oficial da União. 19 Set 1990.

15. Brasil. Ministério da Saúde. Portaria MS/GM no 545, de 20 de maio de 1993. Norma Operacional Básica no 1/1993. Diário Oficial da União. 20 Maio 1993.

16. Brasil. Ministério da Saúde. Portaria MS/GM no 2.203, de 5 de novembro 1996. Norma Operacional Básica no 1/1996. Diário Oficial da União. 5 Nov 1996.

17. Brasil. Ministério da Saúde. Portaria MS/GM no 373, de 27 de fevereiro de 2002. Regionalização da Assistência à Saúde: aprofundando a descentralização com eqüidade no acesso: Norma Operacional da Assistência à Saúde: NOAS-SUS 01/02. Diário Oficial da União. 27 Fev 2002.

18. Brasil. Ministério da Saúde. Portaria MS/GM no 399, de 22 de fevereiro de 2006. Divulga o Pacto 
pela Saúde 2006 - Consolidação do SUS, e aprova as Diretrizes Operacionais do referido pacto. Diário Oficial da União. 22 Fev 2006.

19. Brasil. Ministério da Saúde. Portaria $n^{\circ} 1.473$, de 24 de junho de 2011. Institui os Comitês Gestores, Grupos Executivos, Grupos Transversais e os Comitês de Mobilização Social e de Especialistas dos compromissos prioritários de governo organizados por meio de Redes Temáticas de Atenção à Saúde. Diário Oficial da União. 24 Jun 2011.

20. Magalhães H. Redes de Atenção à Saúde: rumo à integralidade. Divulg Saúde Debate. 2014 Out; (52):15-37.
21. Mendes EV. Comentários sobre as redes de atenção à saúde no SUS. Divulg Saúde Debate. 2014 Out; (52):38-49.

22. Texeira CF. Promoção e vigilância da saúde no contexto da regionalização da assistência à saúde no SUS. Cad. Saúde Pública. 2002; 18(Supl):153-162.

23. Paim J. Modelos de atenção à saúde no Brasil. In: Giovanella L, Escorel S, Lobato LVC, et al., organizadores. Políticas e sistemas de saúde no Brasil. Rio de Janeiro: Fiocruz; 2008. p. 364-459.

Recebido em 05/09/2017

Aprovado em 17/01/2018

Conflito de interesses: inexistente

Suporte financeiro: não houve 